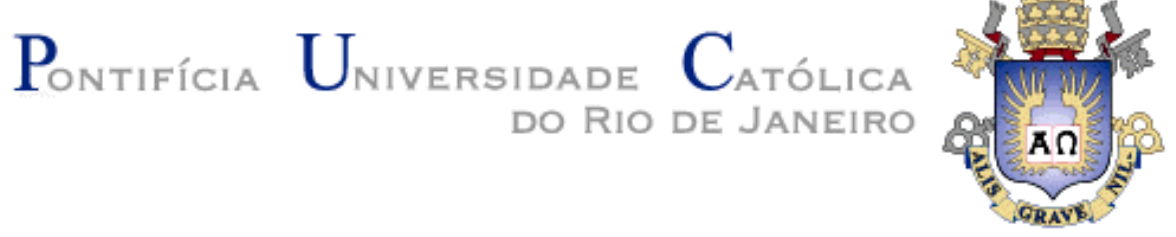

Luciana Muniz Teixeira

Análise Numérica do Comportamento de um Oleoduto sujeito a movimentos de Encosta

Tese apresentada ao Programa de Pós-graduação em Engenharia Civil da PUC-Rio como requisito parcial para obtenção do título de doutor em Engenharia Civil

Orientador: Celso Romanel

Rio de Janeiro, Junho de 2008 


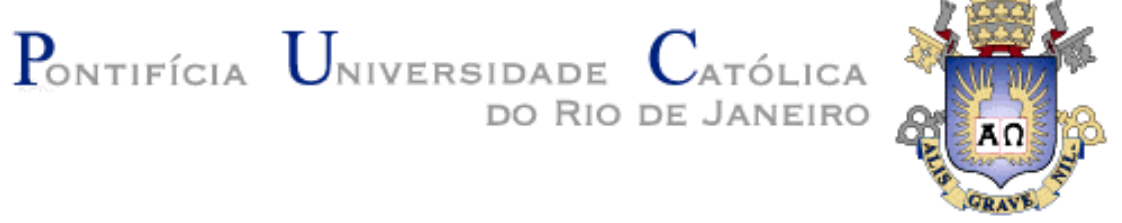

Luciana Muniz Teixeira

\section{Análise Numérica do Comportamento de um Óleoduto Sujeito a Movimentos de Encosta}

Tese apresentada como requisito parcial para obtenção do título de Doutor pelo Programa de Pós-Graduação em Engenharia Civil da PUC-Rio. Aprovada pela Comissão Examinadora abaixo assinada.

Prof. Celso Romanel

Orientador/Presidente

Departamento de Engenharia Civil - PUC-Rio

Prof. Paulo Batista Gonçalves

Departamento de Engenharia Civil - PUC-Rio

Prof. Raul Rosas e Silva

Departamento de Engenharia Civil - PUC-Rio

Profa. Andréa Sell Dyminski

UFPR

Prof. Fernando Saboya Albuquerque Junior

UENF

Prof. José Eugenio Leal

Coordenador Setorial do

Centro Técnico Científico - PUC-Rio

Rio de Janeiro, 04 de junho de 2008. 
Teixeira, Luciana Muniz

Análise numérica do comportamento de um oleoduto sujeito a movimentos de encosta / Luciana Muniz ; orientador: Celso Romanel. - 2008.

123 f. : il. ; $30 \mathrm{~cm}$

Tese (Doutorado em Engenharia Civil)Pontifícia Universidade Católica do Rio de Janeiro, Rio de Janeiro, 2008.

Inclui bibliografia.

1. Engenharia civil - Teses. 2. Estabilidade de talude. 3. Método de elementos finitos. 4. Duto enterrado. 5. Análise 3D. I. Romael, Celso. II. Pontifícia Universidade Católica do Rio de Janeiro. Departamento de Engenharia Civil. III. Título.

CDD: 624 
À Deus, que me acompanhou em cada minuto dessa caminhada, que me concedeu muitas graças e me amparou nos momentos mais difíceis. O seu amor incondicional me presenteou com o essencial : amar-Te mais do que todas as coisas e tudo nos é dado por acréscimo. 


\section{Agradecimentos}

Ao Prof. Celso Romanel pela sua orientação e confiança.

Á Prof. Andrea Dyminski por ter viabilizado a realização dos ensaios na UFPR.

Aos meus pais Eli e Maria da Graça que foram incansáveis durante todo esse período do doutorado, muitas vezes tendo que esperar em DEUS. Obrigada por estarem comigo sempre, não só em presença, mas em apoio e orações. Vocês me ensinaram que o que está além das nossas possibilidades é cuidadosamente resolvido por Deus, que nos criou e nos permite prosseguir.

Ao meu amor, Antonio, que apesar de ter chegado quando o "projeto doutorado" estava bem adiantado, o assumiu junto comigo para que eu chegasse até aqui. O seu incentivo e apoio, frutos do amor, traduzidos em cobranças extremamente necessárias foram cruciais para o fim desse projeto. Agora, nossos projetos são sempre em comum porque escolhemos partilhar a nossa vida com o outro, para sempre!

Aos meus queridos irmãos Leonardo e Thiago por terem sido sempre amigos. Por termos dividido muitos momentos e experiências. A nossa convivência com certeza nos fez mais unidos e comprometidos.

Aos meus primos Karlan, Roger e Pollyana, e Flávia por terem sido a minha família em Curitiba no período da realização dos ensaios.

A todos os amigos que fiz na PUC-Rio. A vocês que viveram junto comigo disciplinas, provas, trabalhos, a convivência na sala 608, o meu muito obrigado.

Ás amigas que fiz na PUC-Rio e fazem parte da minha história pessoal : Nelly Rubio, Cassiane e Patrícia Vitória Vanzan. Vocês são especiais..... 
Á Ir. Graça Maria pelas incansáveis orações, pelo carinho, paciência e direção.

Á Thaís Abreu, Pedro Thá, Roberta Boszczowki, e todos os colegas da UFPR que de alguma forma me auxiliaram na realização dos ensaios e nas atividades desenvolvidas.

À todos os amigos e familiares que rezaram comigo e por mim, que em muitos momentos sentiram a minha ausência. Agradeço a DEUS por vocês existirem.

Finalmente, agradeço ao Autor da vida e à intercessão de Nossa Senhora das Graças: Senhor, tu me abençoastes sempre, em cada passo, em cada decisão. Agradeço-te pela Sua Igreja, pela fé que me fortalece e pelas oportunidades de te servir. Glorificado seja o seu santo nome pois fizestes maravilhas em favor dessa vossa filha. 


\section{Resumo}

Teixeira, L. M.. Análise Numérica do Comportamento de um Oleoduto sujeito a movimentos de Encosta. Rio, 2008. 123p. Tese de Doutorado Departamento de Engenharia Civil, Pontifícia Universidade Católica do Rio de Janeiro.

Movimentos de terra em encostas frequentemente causam grandes prejuízos econômicos, ambientais, sociais e, com freqüência, perda de vidas humanas. $\mathrm{O}$ mecanismo que desencadeia o processo de movimentação geralmente ocorre em períodos de chuvas intensas, principalmente nas encostas com pouca cobertura vegetal ou naquelas que sofreram mudanças recentes na topografia, geralmente pela execução de cortes. Neste trabalho foram realizadas análises de estabilidade da um trecho da encosta da BR-376, que liga as cidades de Curitiba a Joinville no km 55+800 do oleoduto OSPAR da Transpetro. Em 1995, cortes executados para duplicação da rodovia provocaram instabilidade em certa área da encosta. Em janeiro de 1997, durante um período de fortes chuvas, um novo escorregamento da porção inferior do talude provocou a ruptura do muro existente e uma série de escorregamentos sucessivos, que chegaram a atingir a faixa dos oleodutos. Diante desse cenário, utilizou-se primeiramente o programa de elementos finitos PLAXIS para as análises de estabilidade e posteriormente, a fim de comparação, o programa Slope/W e Sigma/W. Para as análises no PLAXIS foi utilizado o hardening soil model para o solo, com os parâmetros sendo determinados através de ensaios triaxiais com amostras obtidas de dois blocos de solo coletados das encosta. Os efeitos da movimentação da encosta no oleoduto OSPAR foram analisados por programa $3 \mathrm{D}$ de elementos finitos, dando-se ênfase às tensões $\mathrm{e}$ deformações para se a fim de verificar a integridade do duto.

\section{Palavras-chave}

estabilidade de talude; método de elementos finitos; duto enterrado; hardening soil model; análise 3D 


\section{Abstract}

Teixeira, L. M.. Numerical Analisys of the Behavior of a Pipeline Subject to mass movement. Rio de Janeiro, 2008. 123p. D. Sc. Thesis Civil Engineering Department, Pontifícia Universidade Católica do Rio de Janeiro.

In densely populated urban areas, landslides generally cause large economic, social and environmental damages as well as, quite frequently, the loss of human lives. The main triggering factor for soil slope failures is the occurrence of heavy rainfalls and the most affected slopes are those with little vegetal covering or that had suffered recent changes in topography, generally due to the execution of cuts and excavations. In this work, stability analyses of a soil slope located at km 55+800 of the Transpetro's OSPAR oil pipeline were carried out In 1995, the works for the duplication of the BR-376 highway, connecting the cities of Curitiba and Joinville, caused some instability in certain area of the soil slope. Later, in January 1997, during a period of heavy rainfall, a new landslide near the slope toe provoked the failure of the existing retaining wall and triggered a series of successive slides that reached the protected area were the oil pipeline was buried. In order to better understand the mechanics involved in this process, numerical analyses were carried out using the computational programs Slope/W, Sigma/W and Plaxis v.8. The soil behavior was simulated considering the hard soil model, whose constitutive parameters were estimated from triaxial tests. The influence of soil movements on the OSPAR oil pipeline were investigated through a 3D finite element analysis, with emphasis on stress and strain distributions in order to check the pile line structural integrity.

\section{Palavras-chave}

Slope stability; finite element method; buried pipeline; hardening soil model; 3D analysis 


\section{Sumário}

1 Introdução

2 Comportamento mecânico de dutos enterrados

20

2.1. Considerações gerais sobre comportamento mecânico de dutos enterrados.

20

2.1.1. Deformações em Dutos 22

2.1.2. Mecânica dos Dutos 24

2.2. Tensões em cilindros estruturais enterrados 24

2.3. Comportamento de Dutos de Concreto Enterrados 28

2.4. Estudo experimental da influência da rigidez relativa duto-solo no momento fletor e no deslocamento vertical do duto 30

2.5. Distribuição de tensões no solo ao redor de dutos enterrados 32

2.6. Distribuição de Tensões ao longo de dutos rígidos enterrados superficialmente 34

2.7. Coeficientes de reação do solo para dutos flexíveis enterrados. $\quad 35$

2.8. Restrição lateral do solo para duto enterrado 37

$\begin{array}{ll}\text { 2.8.1. Ensaio de elemento unitário } & 37\end{array}$

2.8.2. Análise por elementos finitos 38

2.8.3. Cálculos da viga elástica 39

2.9. Previsão da restrição do solo ao duto enterrado usando elementos de interface 40

2.10. Elementos de interface para modelar a reação do solo de fundação para o projeto de duto

2.11. Modelagem por elementos finitos de um duto de polietileno para o sistema de coleta de resíduos de minério de cobre

2.12. Análise elástica de dutos enterrados sujeitos a carregamento na superfície

2.13. Interação solo-duto no movimento lento de encostas - Uma aplicação da análise inversa utilizando o método de elementos de contorno. 
3 Encosta dos oleodutos OSPAR/OPASC

3.1. Histórico 50

3.2. Características do OSPAR e do OPASC 54

3.3. Ensaios de laboratório $\quad 55$

3.3.1. Descrição dos dados pré-existentes 55

3.3.2. Caracterização do material 58

3.3.2.1. Material da Encosta 58

3.3.2.2. Material da cava do duto 59

3.3.3. Ensaio de Cisalhamento Direto 60

3.3.4. Ensaios Triaxiais 62

3.3.4.1. Bloco da Encosta 64

3.3.4.2. Bloco da cava do duto 65

3.3.5. Modelo Constitutivo para o solo 67

4 Estabilidade da Encosta por MEF $\quad 71$

4.1. Introdução 71

4.2. Análise da estabilidade de taludes pelo Método dos elementos finitos7:

4.2.1. Método direto utilizado - simulação de Colapso 74

4.2.2. Método indireto utilizado - equilíbrio Limite Aperfeiçoado 75

4.3. Considerações sobre o método dos elementos finitos 75

4.4. Modelagem com o programa computacional PLAXIS 79

4.4.1. Modelagem da encosta 80

4.4.2. Resultados da análise pelo PLAXIS 84

4.4.2.1. Modelo constitutivo: hardening soil model 84

4.4.2.2. Modelo de solo - Mohr Coulomb 86

4.4.3. Comparação das Análises de Estabilidade pelos programas PLAXIS e Geoslope. $\quad 88$

4.4.3.1. Encosta antes da Duplicação da BR-376 89

4.4.3.2. Encosta com a escavação para a duplicação da BR-376 e contenção - cortina atirantada 90

4.4.3.3. Encosta com a contenção - cortina atirantada - na BR-376 e a jusante da plataforma do duto 92

4.4.4. Análise da encosta com duas simulações: aumento do nível do 
lençol freático e alargamento na BR-376 93

4.4.4.1. Aumento do nível do lençol freático na encosta 93

4.4.4.2. Alargamento da BR-376 em 2 metros 95

4.4.5. Redução do ângulo de atrito para determinação do $\phi$ residual do solo coluvionar. $\quad 96$

4.4.5.1. Análise com $\mathrm{Phi}=27.8^{\circ}$ no Geoslope 97

4.4.5.2. Análise com $\mathrm{Phi}=27.8^{\circ}$ no PLAXIS 98

4.4.5.3. Análise com $\mathrm{Phi}=12,9^{\circ}$ no Geoslope 100

4.4.5.4. Análise de $\phi=13^{\circ}$ no PLAXIS 100

5 Análise 3D do Oleoduto OSPAR 102

5.1. Deslocamento prescrito constante ao longo de z 105

5.2. Deslocamento prescrito variável ao longo de z 110

6 Conclusões e Sugestões $\quad 115$

6.1. Conclusões 115

6.2. Sugestões 116

Referências Bibliográficas $\quad 118$

$\begin{array}{ll}\text { Anexo } 1 & 122\end{array}$ 


\section{Lista de figuras}

Figura 1 Força lateral no duto devido ao transporte e instalação (Adaptado de

$\begin{array}{ll}\text { Watkins and Anderson, 2000) } & 21\end{array}$

O caso básico analisado é mostrado na 25

Figura 2 Análise por deformação plana (Höeg, 1968) 26

Um carregamento normal é aplicado sobre os quatro contornos ilustrados na 26

Figura 3 Esquema da caixa do ensaio experimental 31

Figura 4 Momento fletor avaliado a partir de deformações ao longo do duto sob areia. Ângulo de acamamento de $90^{\circ}$ e $85 \%$ de compactação Proctor Normal (Shmulevich and Galili - 1986)

Figura 5 Momento fletor avaliado a partir de deformações ao longo do duto sob areia. Ângulo de acamamento de $120^{\circ}$ e $97 \%$ de compactação Proctor Normal (Shmulevich and Galili - 1986) 32

Figura 6 Resultados do ensaio do elemento unitário ( $\mathrm{Ng}$ et al, 1994) 38

Figura 7 Malha de elementos finitos 2-D (Ng et al, 1994) 39

Figura 8 Resultados previstos para a partir de uma viga elástica em um programa de fundações sob carregamento de $296 \mathrm{kN}$ (Ng et al, 1994) 40

Figura 9 duto segmentado (Backer et al, 1997) 42

Figura 10 modelo de elementos finitos para um duto segmentado; os anéis possuem a mesma coordenada (Backer et al, 1997) 42

Figura 11 elemento de viga de cinco nós (Backer et al, 1997) 43

Figura 12 elemento de interface de dez nós (Backer et al) 43

Figura 13 Malha de elementos finitos típica utilizada na análise (Fernando e

Carter, 1998) 46

Figura 14 Superfície de deslocamento estimada através de medidas de inclinômetros e furos de sondagem (Mandolini et al, 2001) 48

Figura 15 - Localização dos oleodutos OSPAR/OPASC 49

$\begin{array}{lr}\text { Figura } 16 \text { Vista da plataforma dos dutos } & 50\end{array}$

Figura 17 Forma esquemática das fendas ao longo da encosta, dentro da área da coberta por vegetação (Vasconcelos, 1997) 51 
Figura 18 Esboço dos tipos de solo da encosta 51

Figura 19 Cortina atirantada feita pelo DNER na BR-372 52

Figura 20 Esboço do perfil de solo simplificado considerado nas análises de estabilidade feitas pela Geoprojetos. 56

Figura 21 Coleta do bloco da encosta na variante do GASBOL. 57

Figura 22 Coleta do bloco da cava do duto 58

Figura 23 Curva de distribuição granulométrica do material da encosta do $\mathrm{Km}$ 55+800 do OSPAR 59

Figura 24 Curva granulométrica do material da cava do duto 60

Figura 25 Prensa do cisalhamento (a) e caixa de ensaio (b) 61

Figura 26 Determinação de c e $\phi$ para o bloco da encosta na condição submerso:

(a) Tensão normal x tensão cisalhante (b) deslocamento horizontal x tensão cisalhante

61

Figura 27 Determinação de c e $\phi$ para o bloco da encosta na condição nãosubmerso: (a) Tensão normal x tensão cisalhante (b) deslocamento horizontal $\mathrm{x}$ tensão cisalhante

61

Figura 28 Determinação de c e $\phi$ para o bloco da encosta na condição submerso:

(a) Tensão normal x tensão cisalhante (b) deslocamento horizontal x tensão cisalhante

Figura 29 Determinação de c e $\phi$ para o bloco da encosta na condição nãosubmerso: (a) Tensão normal x tensão cisalhante (b) deslocamento horizontal $\mathrm{x}$ tensão cisalhante $\quad 62$

Figura 30 Prensa Triaxial GDS 63

Figura 31 Moldagem do corpo de prova $\quad 63$

Figura 32 Gráfico $\sigma_{\text {desv }} \times \varepsilon(\%)$ do ensaio triaxial drenado para o bloco da encosta

64

Figura 33 Gráfico deformação axial x deformação volumétrica do bloco da $\begin{array}{ll}\text { encosta } & 64\end{array}$

Figura 34 Gráfico p x q do ensaio triaxial para determinação dos parâmetros c e $\phi$ - bloco da encosta

Figura 35 Gráfico $\sigma_{\text {desv }}$ x $\varepsilon(\%)$ do ensaio triaxial drenado para o bloco da cava do duto 66

Figura 36 Gráfico deformação axial x deformação volumétrica do bloco da cava do duto 
Figura 37 Gráfico p x q do ensaio triaxial para determinação dos parâmetros c e $\phi$ - bloco da cava do duto

Figura 38 Relação hiperbólica tensão x deformação no carregamento primário para o ensaio triaxial (Material Model Manual V8 - Plaxis - modificado) 68

Figura 39 Definição do $E_{\text {oed }}^{r e f}$ a partir do resultado do ensaio oedométrico 69

Figura 40 Comparação das Curvas $\sigma_{\text {desv }}$ x $\varepsilon(\%)$ dos ensaios e do modelo HS para o solo da encosta.

Figura 41 Comparação das Curvas $\sigma_{\text {desv }} \times \varepsilon(\%)$ dos ensaios e do modelo HS para o solo da cava do duto. 70

Figura 42 Seção transversal da encosta onde foram feitas as análises. $\quad 83$

$\begin{array}{ll}\text { Figura } 43 \text { Encosta com o duto } & 84\end{array}$

Figura 44 Malha de elementos finitos deformada - modelo Hardening Soil para o solo

Figura 45 Deslocamentos totais no final da análise - modelo Hardening Soil para o solo 85

Figura 46 Tensões totais no final da análise considerando o hardening soil model

86

Figura 47 Malha de elementos finitos deformada considerando o modelo de Mohr Coulomb. 86

Figura 48 Deslocamentos totais no final da análise considerando o modelo de Mohr Coulomb.

Figura 49 Tensões totais no final da análise considerando o modelo de Mohr Coulomb. 88

Figura 50 Superfície de ruptura do talude sem a escavação para a duplicação da BR-376 com fator de segurança igual a 1,160 - Programa PLAXIS 89

Figura 51 Superfície de ruptura do talude sem a escavação para a duplicação da BR-376 com fator de segurança igual a 1,174 - Slope/W 90

Figura 52 Superfície de ruptura do talude sem a escavação para a duplicação da BR-376 com fator de segurança igual a 0,726 - tensões calculadas por elementos finitos pelo Sigma/W - análise de estabilidade utilizando o Slope/W

Figura 53 Superfície de ruptura do talude com a escavação para a duplicação da BR-376 e os tirantes de contenção com fator de segurança igual a 1,144 Programa PLAXIS 
Figura 54 Superfície de ruptura do talude com a escavação para a duplicação da BR-376 e os tirantes de contenção com fator de segurança igual a 1,274 Slope/W

Figura 55 Superfície de ruptura do talude com a escavação para a duplicação da BR-376 e os tirantes de contenção com fator de segurança igual a 1,194 tensões calculadas por elementos finitos pelo SIGMA/W - análise de estabilidade utilizando o Slope/W 92

Figura 56 Superfície de ruptura do talude com tirantes de contenção na BR-376 e a jusante da plataforma do duto, com fator de segurança igual a 1,139 Programa PLAXIS

Figura 57 Superfície de ruptura do talude com tirantes de contenção na BR-376 e a jusante da plataforma do duto, com fator de segurança igual a 1,278 Slope/W

Figura 58 Superfície de ruptura do talude com os tirantes de contenção na BR-376 e a jusante da plataforma do duto com fator de segurança igual a 1,181tensões calculadas por elementos finitos pelo SIGMA/W - análise de estabilidade utilizando o Slope/W 93 deslocamento total máximo $=2,59 \mathrm{~m}$ 94

Figura 59 Deslocamentos totais para a simulação do aumento do nível do lençol freático 94

Figura 60 Deslocamentos totais para o cálculo do fator de segurança 95

Figura 61 Deslocamento total para alargamento de 2m na BR-376 96

Figura 62 Análise no Geoslope. Superfície de ruptura definida. 97

Figura 63 Resultado da análise no Geoslope com $\phi=27,8^{\circ}-$ Fator de Segurança igual a $2,044 \quad 98$

Figura 64 Malha de elementos finitos para análise no PLAXIS 98

Figura 65 Deslocamento total - Análise no Plaxis $-\phi=27.8^{\circ} 99$

Figura 66 Deslocamentos totais para o cálculo do fator de segurança $-\phi=27.8^{\circ} 99$

Figura 67 Resultado da análise no Geoslope com $\phi=12,9^{\circ}-$ Fator de Segurança $\begin{array}{ll}\text { igual a } 0,995 & 100\end{array}$

Figura 68 Deslocamentos totais - Análise no Plaxis $-\phi=13^{\circ} \quad 101$

Figura 69 Deslocamentos totais para o cálculo do fator de segurança $-\phi=13^{\circ} 101$

Figura 70 Fatia da encosta utilizada para as análises do oleoduto OSPAR 102

Figura 71 Diagrama de momento fletor para uma viga bi-engastada. 103 
Figura 72 - Deslocamento prescrito constante em todo comprimento do bloco (deslocamento de corpo rígido)

Figura 73 - Deslocamento prescrito variável - zero para $\mathrm{z}=0$ e $\mathrm{z}=130 \mathrm{~m}$ e máximo para $\mathrm{z}=65 \mathrm{~m}$

Figura 76 malha deformada - deslocamento prescrito constante - plano da frente

Figura 77 Malha deformada - deslocamento prescrito constante - plano A 107

Figura 78 Deslocamento horizontal - deslocamento prescrito constante - (a) plano da frente e (b) plano A

107

Figura 79 Deslocamento vertical - deslocamento prescrito constante - (a) plano da frente e (b) plano A

108

Figura 80 Tensão total média - deslocamento prescrito constante - (a) plano da frente (b) plano A

108

Figura 81 Deslocamentos horizontais do duto - (a) plano da frente (b) plano A 109 Figura 82 Deslocamentos verticais do duto - (a) plano da frente (b) plano A 109 Figura 83 Malha deformada - deslocamento prescrito variável - plano da frente

Figura 84 Malha deformada - deslocamento prescrito variável - plano A

Figura 87 Deslocamento horizontal - deslocamento prescrito variável (a) plano da frente e (b) plano A

Figura 88 Deslocamento vertical - deslocamento prescrito variável - (a) plano da frente e (b) plano A

Figura 89 Tensão total média - deslocamento prescrito constante - (a) plano da frente (b) plano A

Figura 90 Deslocamentos horizontais do duto - deslocamento prescrito variável (a) plano da frente (b) plano A

Figura 91 Deslocamentos verticais do duto - deslocamento prescrito variável - (a) plano da frente (b) plano A 


\section{Lista de tabelas}

Tabela 1 Parâmetros hiperbólicos utilizados para elementos de solo 35

Tabela 2 Dados dos oleodutos OSPAR e OPASC (Vasconcelos, 1997) 55

Tabela 3 Parâmetros do solo da encosta $\quad 56$

Tabela 4 Parâmetros c e $\phi$ para o solo da encosta e da cava do duto 60

Tabela 5 Propriedades dos solos $\quad 81$

Tabela 6 Propriedades da Cortina Atirantada 81

Tabela 7 Propriedades dos tirantes e do bulbo de ancoragem 81

Tabela 8 Posição do lençol freático em relação à rodovia BR-376 (afastamento=0; $\operatorname{cota}=76,5 \mathrm{~m}) \quad 82$

Tabela 9 Nível do lençol freático original e proposto em relação a rodovia BR-376 (afastamento $=0 ; \operatorname{cota}=76,5 \mathrm{~m}) \quad 94$ 